\title{
Music at BNCC and the possibilities of applying Computational Thinking using Scratch
}

\author{
Graziela Ferreira Guarda ${ }^{1,2}$, Julián Alberto García García ${ }^{1}$ \\ ${ }^{1}$ Escuela Técnica Superior de Ingeniería Informática - Universidad D Sevilla \\ ${ }^{2}$ Programa de Pós-Graduação em Ciências, Tecnologias e Inclusão - UFF \\ graziela.ferreira@iwt2.org; juliangg@us.es

\begin{abstract}
Music is a very favorable field of knowledge for the development of creativity. With this in mind, this paper presents results of investigate the role of music in the school curriculum in the three stages of Brazilian Elementary Education. For this, a qualitative approach of descriptive nature was used, exploring the guidelines for the teaching of music at National Education Standards (BNCC) and, at the end, purpose an activity for the application of Computational Thinking (CT) using Scratch as potential tool for creative mediation in the field of song. The proposed activity is in line with both the $B N C C$ guidelines and the pillars of the CT and can be adapted to all types of teaching: face-to-face, online, distance education and hybrid.
\end{abstract}

\section{Introduction}

Music is a universal human language. The relationship between sounds, silences, corporeality, rhythm are present in the most diverse communities and peoples, evidenced by rituals, parties, games. Still, music is the first artistic expression that human beings have contact with, because even before birth, the sound-musical environment is already experienced through speech and maternal songs and through the rich intrauterine sounds. From another perspective, "Music is a form of expression, it is aesthetic development, cultural manifestation and, therefore, having access to this content is as important as any other" [Duarte 2010, p. 33].

However, according to [Fucci-Amato 2012], there is a panorama of absence of musical culture for almost 40 years in Brazilian schools. This means that active teachers, if they did not have the opportunity to experience musical practices in extra-school environments, possibly did not go through any or very rare musical experiences in the school environment. In this context, it is important to train teachers and share new paths and strategies for teaching music in the school environment, seeking to enrich interdisciplinary actions.

In this direction, the present study aims to investigate to emphasize the importance of music in the teaching and learning process, seeking: 1) to identify and analyze the guidelines for the teaching of music at National Education Standards (BNCC) and 2) to present possibilities for the exercise of Computational Thinking (CT) skills using Scratch as a mediation tool in the area of music.

The article is structured as follows: Section 2 presents the methodological approach. Section 3 shows how the music is arranged at BNCC. In section 4, the fundamentals of the CT are introduced, in Section 5 it is shown how to work the music associated with the 
CT and finally, conclusions and future work will be shown in Section 6.

\section{Methodological approach}

So that the objectives could be achieved, we chose to carry out a qualitative descriptive research. According to [Bresler 2007. p. 13] "cultural sciences need to be descriptive as well as explanatory and predictable". The author defends qualitative research in music education, as this is how we can embrace the variety of cultural, institutional and personal contexts that music education involves.

This type of research allows an investigation that allows us to show the expectations of musical education in any educational context. As this is a research that sought the interrelationship of the macrosystem to the micro, the references and guidelines of the Arts and Music components at BNCC were analyzed in their entirety. In addition, the study directs and brings indicators and an activity "model" to enable the integration of Computational Thinking in music teaching.

\section{Music and BNCC}

This section aims to show how music is arranged at the BNCC, what are the learning objectives or objects and what skills are expected to be developed in this theme with Basic Education students. To this end, it is clarified that the BNCC is structured in three stages: Early Childhood Education (BNCC-EC), Elementary School (BNCC-ES) and High School (BNCC-HS) [BRASIL 2017].

Regarding the BNCC-EI, it seeks to guarantee the learning and development rights of children, which are: socialize, play, participate, explore, express and know themselves. Based on these, the document establishes the five Fields of Experience: 1) the self, the other and the us; 2) body, gestures and movements; 3) traces, sounds, colors and shapes; 4) listening, speaking, thinking and imagining; and 5) spaces, times, quantities, relationships and transformations. In this perspective, the learning and development objectives in the field of experiences 3 are described in Table 1 below:

Table 1. Learning and Development Objectives - BNCC-EC

\begin{tabular}{|c|c|c|c|}
\hline Age group: & $\begin{array}{l}\text { Babies (zero to } 1 \\
\text { year and } 6 \\
\text { months) }\end{array}$ & $\begin{array}{l}\text { Very young children ( } 1 \\
\text { year and } 7 \text { months to } 3 \\
\text { years and } 11 \text { months) }\end{array}$ & $\begin{array}{l}\text { Small children ( } 4 \text { years to } \\
5 \text { years and } 11 \text { months) }\end{array}$ \\
\hline Obj & $\begin{array}{l}\text { EI01TS01 } \\
\text { Explore sounds } \\
\text { produced with } \\
\text { your own body } \\
\text { and with objects in } \\
\text { the environment. }\end{array}$ & $\begin{array}{lr}\text { EI02TS01 } & \text { Create } \\
\text { sounds with materials, } \\
\text { objects and musical } \\
\text { instruments } \\
\text { accompany to } \\
\text { rhythms of musician. }\end{array}$ & $\begin{array}{l}\text { EI03TS01 - Using sounds } \\
\text { produced by materials, } \\
\text { objects and musical } \\
\text { instruments during make- } \\
\text { believe games, staging, } \\
\text { musical creations, parties. }\end{array}$ \\
\hline
\end{tabular}

Regarding the BNCC-ES (Cycle 1 - Elementary School), the teaching of Art must ensure students the possibility of expressing themselves creatively in their investigative work, through playfulness, providing an experience of continuity in relation to Early Childhood Education. Thus, it is important that, in the four languages of Art integrated by the six dimensions of artistic knowledge, artistic experiences and experiences are centered on the interests of children and children's cultures.

In this cycle, the commitment is to ensure students the development of skills related to literacy and literacy, the Art component, by providing access to reading, 
creation and production in various artistic languages, contributes to the development of skills related to both to verbal language as to non-verbal languages. In this perspective, the objects of knowledge and learning are described in Table 2:

\section{Table 2. Objects of Knowledge and Skills - BNCC-ES (Elementary School)}

\begin{tabular}{|l|l|}
\hline $\begin{array}{l}\text { Context and } \\
\text { Practice }\end{array}$ & $\begin{array}{l}\text { EF15AR13 - Identify and critically appreciate different forms and genres of } \\
\text { musical expression, recognizing and analyzing the uses and functions of } \\
\text { music in different contexts of circulation, especially those of everyday life. }\end{array}$ \\
\hline $\begin{array}{l}\text { Language } \\
\text { Elements }\end{array}$ & $\begin{array}{l}\text { EF15AR14 - Understand and explore the constituent elements of music } \\
\text { (pitch, intensity, timbre, melody, rhythm, etc.), through games, games, } \\
\text { songs and various practices of composition/creation, performance and } \\
\text { musical appreciation. }\end{array}$ \\
\hline Materiality's & $\begin{array}{l}\text { EF15AR15 - Explore different sound sources, such as those existing in the } \\
\text { body itself (palms, voice, body percussion), in nature and in everyday } \\
\text { objects, recognizing the constituent elements of music and the } \\
\text { characteristics of various musical instruments. }\end{array}$ \\
\hline $\begin{array}{l}\text { Notation and } \\
\text { musical record }\end{array}$ & $\begin{array}{l}\text { EF15AR16 - Explore different forms of unconventional music recording } \\
\text { (graphic representation of sounds, creative scores, etc.), as well as audio } \\
\text { and audiovisual recording procedures and techniques, and recognize } \\
\text { conventional music notation. }\end{array}$ \\
\hline $\begin{array}{l}\text { Creation } \\
\text { Processes }\end{array}$ & $\begin{array}{l}\text { EF15AR17 - Experiment with improvisations, compositions and sounding } \\
\text { of stories, among others, using voices, body sounds and/or conventional or } \\
\text { unconventional musical instruments, individually, collectively and } \\
\text { collaboratively. }\end{array}$ \\
\hline
\end{tabular}

Regarding the BNCC-EF (Cycle 2 - Middle School), the base proposes that it is necessary to ensure that students expand their interactions with national and international artistic and cultural manifestations, from different times and contexts. These practices can occupy the most diverse spaces in the school, spreading to its surroundings and favoring relationships with the community. In addition, the differential of this phase is the greater systematization of knowledge and the proposition of more diversified experiences in relation to each language, considering youth cultures. In this way, it is expected that the Art component contribute to the deepening of learning in different languages and in the dialogue between them and with other areas of knowledge, with a view to allowing students greater autonomy in artistic experiences and experiences. In this perspective, the objects of knowledge and learning are described in Table 3:

Table 3. Objects of Knowledge and Skills - BNCC-ES (Middle School)

\begin{tabular}{|l|l|}
\hline Context & and \\
Practice & $\begin{array}{l}\text { EF69AR16 - Critically analyze, through musical appreciation, uses and } \\
\text { functions of music in their contexts of production and circulation, relating } \\
\text { musical practices to different dimensions of social, cultural, political, } \\
\text { historical, economic, aesthetic and ethical life. } \\
\text { EF69AR17 - Explore and critically analyze different cultural media and } \\
\text { equipment for the circulation of music and musical knowledge. } \\
\text { EF69AR18 - Recognize and appreciate the role of Brazilian and foreign } \\
\text { musicians and music groups that contributed to the development of musical } \\
\text { forms and genres. } \\
\text { EF69AR19 - Identify and analyze different musical styles, contextualizing } \\
\text { them in time and space, in order to improve the ability to appreciate musical } \\
\text { aesthetics. }\end{array}$ \\
\hline Language & EF69AR20 - Explore and analyze the constitutive elements of music (pitch, \\
\hline
\end{tabular}




\begin{tabular}{|l|l|}
\hline Elements & $\begin{array}{l}\text { intensity, timbre, melody, rhythm, etc.), through technological resources } \\
\text { (games and digital platforms), games, songs and various musical } \\
\text { composition/creation, performance and appreciation practices. }\end{array}$ \\
\hline Materiality's & $\begin{array}{l}\text { EF69AR21 - Explore and analyze sound sources and materials in } \\
\text { composition/creation, performance and musical appreciation practices, } \\
\text { recognizing timbres and characteristics of different musical instruments. }\end{array}$ \\
\hline $\begin{array}{l}\text { Notation and } \\
\text { musical record }\end{array}$ & $\begin{array}{l}\text { EF69AR22 - Explore and identify different forms of musical recording } \\
\text { (traditional musical notation, creative scores and contemporary music } \\
\text { procedures), as well as audio and audiovisual recording procedures and } \\
\text { techniques. }\end{array}$ \\
\hline $\begin{array}{l}\text { Creation } \\
\text { Processes }\end{array}$ & $\begin{array}{l}\text { EF69AR23 - Explore and create improvisations, compositions, } \\
\text { arrangements, jingles, soundtracks, among others, using voices, body } \\
\text { sounds and/or acoustic or electronic instruments, conventional or } \\
\text { unconventional, expressing musical ideas in an individual, collective and } \\
\text { collaborative way. }\end{array}$ \\
\hline
\end{tabular}

Regarding BNCC-HS, the Art component contributes to the development of reflective, creative and expressive autonomy of students, through the connection between thought, sensitivity, intuition and playfulness. The proposal for the progression of learning in High School foresees the deepening of research and development of authorial creation processes in the languages of the visual arts, audiovisual, dance, theater, circus arts and music. In this perspective, the objects of knowledge and learning are described in Table 4:

\section{Table 4. Objects of Knowledge and Skills - BNCC-HS}

\begin{tabular}{|l|l|}
\hline $\begin{array}{l}\text { Social } \\
\text { Action: }\end{array}$ & $\begin{array}{l}\text { EM13LP13 - Analyze, from contextual, aesthetic and cultural references, } \\
\text { meaning effects resulting from choices of sound elements (volume, timbre, } \\
\text { intensity, pauses, rhythm, sound effects, synchronization, etc.) and their } \\
\text { relationship with the verbal, taking them into account in the production of } \\
\text { audios, to expand the possibilities of construction of meanings and appreciation. }\end{array}$ \\
\hline $\begin{array}{l}\text { Personal } \\
\text { life: }\end{array}$ & $\begin{array}{l}\text { EM13LP21 - Collaboratively produce and socialize commented playlists of } \\
\text { cultural and entertainment preferences, cultural magazines, fanzines, e-zines or } \\
\text { related publications that publicize, comment and rate music, games, series, } \\
\text { movies, comics, books, plays, exhibitions, dance shows etc., in order to share } \\
\text { tastes, identify affinities, foster communities etc. }\end{array}$ \\
\hline
\end{tabular}

In summary, it is important to understand that the presence of music education, from kindergarten onwards, has the role of enhancing musicality and musicalization - these topics contribute to social, affective, cognitive, psychological development, among others, and in this sense, the educator is a very important figure, as he will be the driver of this knowledge that will be transmitted through oral and/or experiential communication and in light of this reality, it is observed that the BNCC is concerned with musicalization proposals, in order to enrich the musical experiences and experiences of students.

In parallel, BNCC brings in the field of language in the digital universe, the skill EM13LGG701 - Explore digital information and communication technologies (DICT), understanding its principles and functionalities, and using them in an ethical, creative, responsible and appropriate way to practices of language in different contexts and it is clear that digital technologies have influenced the current society, in a broad way, and the field of music was also influenced by these technologies. Consequently, also the field of 
music education and in this perspective, Computational Thinking is found as a potential tool for a creative and digital exploration of the Arts.

\section{Computational Thinking}

In 1980, Seymour Papert already saw the computer as a stimulator of ideas and visualized the possibilities of using it to innovate the educational system. In his work, [Papert 1985] stated that the interaction was guided by children teaching the computer to perform tasks, and never in the opposite direction. Thus, the computer becomes an ally in the construction of knowledge and an influencer of human thought.

The reflection on the CT originated from how computer scientists think, which are skills that have become fundamental for everyone who can find their way into the world of technology and, consequently, expand their ability to solve problems. In this sense, [Wing 2006] states that, in addition to reading, writing and arithmetic, the dimensions of the CT must be added to everyone's analytical capacity. Similarly, a decade before Wing's propositions, [Papert 1996] suggested introducing CT dimensions in a way that would allow people to better analyze and solve problems, develop solutions, and establish connections between them. Otherwise, CT can be understood as an approach aimed at solving problems by exploring cognitive processes. They address students' ability to understand proposed situations and create solutions through mathematical, scientific, or social models resulting in increased productivity, inventiveness, and creativity [Guarda and Pinto 2020].

CT skills have been recognized by computer science education organizations as part of the skill set that need to be developed at various school levels. Thus, presenting the pillars of the CT: decomposition: involves identifying a complex problem and breaking it down into smaller, easier-to-manage pieces; pattern recognition: each of these smaller problems can be analyzed individually in greater depth, identifying similar problems that have already been solved before; abstraction: ability to filter essential information and discard unnecessary information in a given context and algorithms: logical sequences to achieve a goal, with abstraction considered the essence of this type of thinking.

\section{Computational Thinking in Music Teaching}

The objective of education through music is the child, their education, their formation as a being, as a person and the balanced development of their personality. The goal is the child and not the music. Thus, the teacher's knowledge of the field of pedagogy and psychology is more important than musical knowledge necessarily. Therefore, it is not necessary for the teacher to have knowledge of musical writing or to know how to play an instrument and there are many ways to motivate students to develop musical expression and creation.

Thus, the educator is interested in integrating the child into the sound universe (listening, locating, exploring, experimenting, understanding), and also using music for the expression and development of creativity. From this point of view, [Schafer 2011] helps us to reflect on a curriculum in music education that considers the study of sound and silence, as a laboratory of multiple analytical possibilities of its elements alone, and in articulation in the composition of landscapes sounds, such as: timbre, amplitude, melody, texture, rhythm, etc. The author treats music education in an accessible way to all elementary school teachers, building viable conditions for the universalization of 
music education.

The fact is that there are several ways to work music at school, for example, in a playful and collective way, using games, wheel games, instrument making and even through the use of digital resources that promote the development of Computational Thinking skills that appears as a possibility for a broader learning, favoring the development of knowledge necessary to support the teaching and learning of students also in the music component.

In parallel, we are (still) experiencing the impacts of the COVID-19 pandemic brought to our routines, which caused significant and sudden changes in our lives [Dubey et al., 2020]; [Singh et al., 2020]. Thus, there is a more urgent need for debates on how educational models can be adapted to meet new needs, while numerous challenges have been encountered in the forms of distance education that are still being implemented in most countries. These challenges include technological support for students to monitor activities, standardization of actions and procedures, and teacher training/adaptation.

Therefore, it is essential to engage students and encourage them to speak, write and do through digital media, to help them improve, reinvent themselves and, above all, to be resilient. Critical reflection on these issues is an essential contribution both to the educational strategies adopted during the pandemic and to those that will be adopted in the post-pandemic scenario and thinking about the use of DICT's and their "new value", if Scratch stands out as distinctive feature to be used in the field of music.

The Scratch educational application stands out for using design-oriented development concepts - block programming logic and through the use of this tool, the individual does not need to know syntax or algorithmic structures to get their first experiences with programming.

Scratch is a graphical programming language, inspired by the Logo and Squeak languages. The language was invented for children to create programs without the need to know coding. Instead, they program through blocks of commands that are nested together, forming a set of instructions. Its aim is to facilitate the introduction of math and computing concepts, while at the same time inducing creative thinking, systematic reasoning and collaborative work. In this sense, Scratch allows the creation of programs that control and mix images, animation, text, music and sound [Zhang and Nouri 2019].

Scratch allows in the field of Arts, the creation of music using different musical instruments that can be used individually or together. The musical instruments available on the platform are: snare drum, bass drum, side stick, crash cymbal, open hi-hat, closed hi-hat, tambourine, hand clap, claves, wood block, cowbell, triangle, bongo, conga, babasa, guiro, vibraslap and cuica.

As a "model" of activity, it was proposed the development of an algorithm in the Scratch of Happy Birthday music to demonstrate how the development of Computational Thinking skills occurs. The algorithm solution should be represented by sequences of simple and direct instructions in Scratch and the use of repetition structures can be made. Table 5 below demonstrates the problem to be solved in detail:

Table 5. Description of the proposed problem as a pedagogical activity

\begin{tabular}{|l|l|}
\hline $\begin{array}{l}\text { Problem } \\
\text { Overview: }\end{array}$ & $\begin{array}{l}\text { Analysis of the problem, defining it through its inputs (resources/inputs) } \\
\text { and expected outputs. }\end{array}$ \\
\hline Objectives: & Develop a Happy Birthday song algorithm using at least two free-choice \\
\hline
\end{tabular}




\begin{tabular}{|l|l|}
\hline \multicolumn{1}{|c|}{ to be } & musical instruments in Scratch. \\
resolved: & $\begin{array}{l}\text { 1. Remember the memorized music; } \\
\text { 2. Identify the different musical instruments available in Scratch; } \\
\text { 3. Hear and recognize the different sounds produced by musical } \\
\text { instruments; } \\
\text { 4. Define the two musical instruments to be used in making the music } \\
\text { (inputs) and which will be the main instrument; } \\
\text { 5. Write the logical sequence of sounds correctly that most closely matches } \\
\text { the song (output). }\end{array}$ \\
\hline Skills worked: & $\begin{array}{l}\text { Understand the problem definition as a relationship between input (inputs) } \\
\text { and output (outcome); } \\
\text { Understand what can be processed and how; } \\
\text { Remember memorized music; } \\
\text { Write and create or improvise music. }\end{array}$ \\
\hline Methodology: & $\begin{array}{l}\text { Step 1: Define the problem in terms of its inputs and outputs; } \\
\text { Step 2: Analyze and establish what the inputs are; } \\
\text { Step 3: Analyze and establish what are the outputs or results to be produced; } \\
\text { Step 4: Understand and define how the processing will take place. }\end{array}$ \\
\hline Materials: & $\begin{array}{l}\text { Computer, internet access, Scratch, paper and pencil if necessary to } \\
\text { transpose the exercise of silence in the process of mentally recalling music. }\end{array}$ \\
\hline $\begin{array}{l}\text { Expected } \\
\text { results: }\end{array}$ & $\begin{array}{l}\text { The Happy Birthday song complete with a sequence of sounds recognizable } \\
\text { by anyone. }\end{array}$ \\
\hline
\end{tabular}

The proposed activity can be implemented in all existing educational modalities: face-to-face teaching, distance education (ED), online or hybrid teaching. It is an example of a fully adaptable activity (the Happy Birthday song was chosen because it is widely known by people of all ages) and can be applied in the context of online classes as both a synchronous and asynchronous activity.

As a solution to the proposed problem, the algorithm below is presented (Figure 1), which was divided into 4 parts for better visualization of the result - it represents a single sequence and must be read from left to right. For this purpose, the two musical instruments chosen were the hit-hat cymbal to open the song (this instrument has the sound of drum cymbals) and the piano was chosen as the main instrument.

The parts of the song that were repeated were placed with looping control (repeat command) and it is also highlighted that the proposed solution is one (of several) possible solutions for the same problem and that it is in line with the BNCC guidelines of two of the three stages (Elementary School (BNCC-ES) and High School (BNCC-HS)).

At the same time, considering possible adaptations of the proposed activity, it is suggested to differentiate the levels of complexity of the songs to be proposed according to the student's knowledge.

If the student has no musical knowledge or has never produced digital music, it is suggested that the music to be worked on should be of an easy level. In this case, some examples are: Happy Night or Falls falls balloon.

If the student has some notion of musical knowledge or has already produced digital music, it is suggested that the music to be worked on should be of medium level. In this case some examples are: Jesus Bleibet Meine Freude (Jesu Joy of Man`s) - JS Bach or Clocks - Coldplay. 
If the student has musical knowledge or has already produced digital music, it is suggested that the music to be worked on is of a difficult level. In this case, some examples are Fur Elise - Beethoven that needs parallelism where it is necessary to develop parallel algorithms (left hand) and another (right hand) or Turkish March Mozart or create a song using different musical instruments.

Remembering that it is important to respect (listen to) the student's musical preference as well.

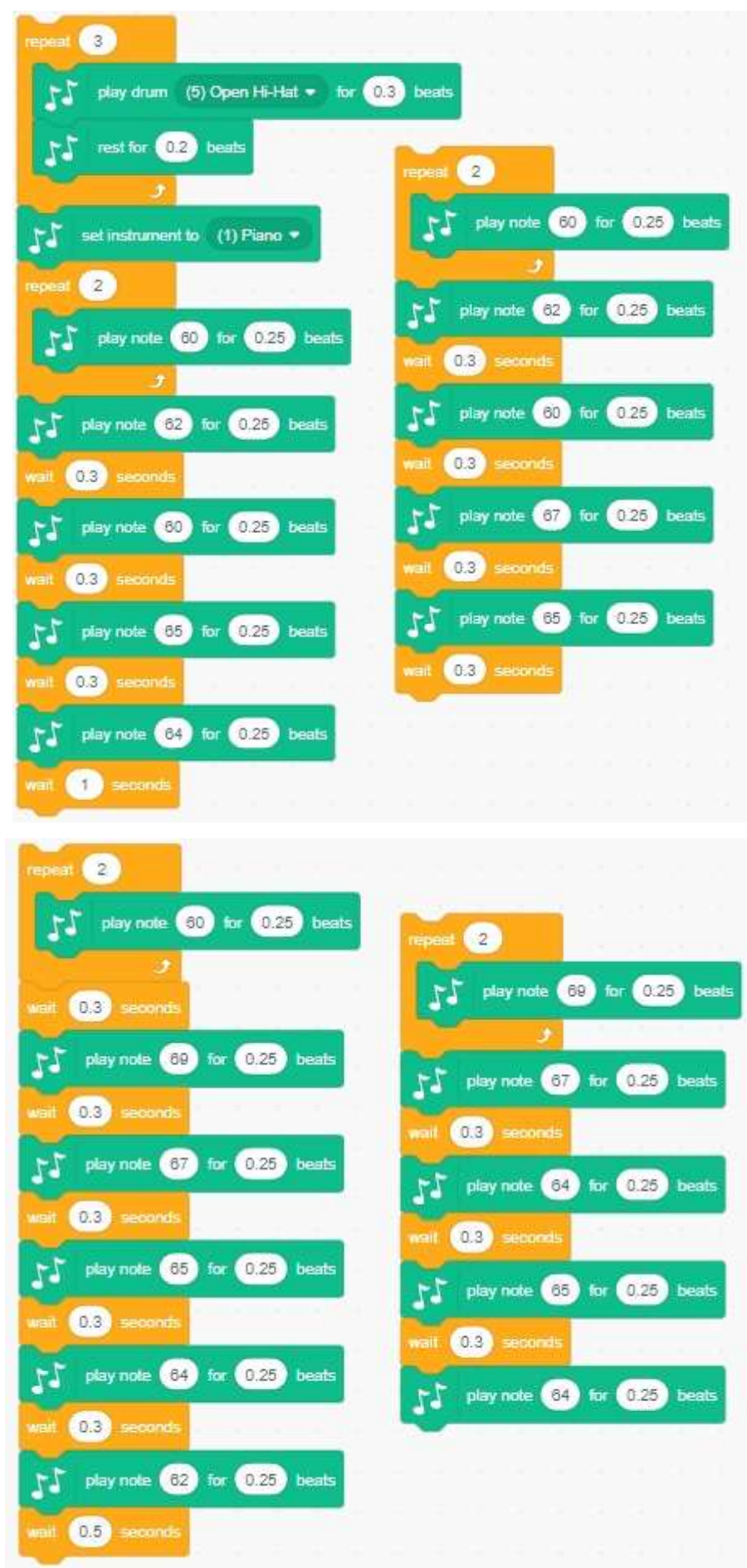

Figure 1. Description of the solution to the problem proposed in Scratch. 
The developed music algorithm explores all the abilities of the pillars of Computational Thinking and Table 6 shows these relationships and associates which stage(s) - 3rd row of Table 5 - is associated with the ability.

Table 6. Relationship of CT Skills to Scratch Music Development

\begin{tabular}{|l|l|l|}
\hline \multicolumn{1}{|c|}{ CT Skills: } & \multicolumn{1}{|c|}{ Development steps: } & \multicolumn{1}{|c|}{$\begin{array}{l}\text { Associated } \\
\text { with Step: }\end{array}$} \\
\hline Abstraction & $\begin{array}{l}\text { Perform problem interpretation. } \\
\text { Identify which sounds of the musical instrument are close to } \\
\text { the music. } \\
\text { Eliminate unnecessary details. }\end{array}$ & $\begin{array}{l}1,2,3 \text { and } \\
5 .\end{array}$ \\
\hline Decomposition & $\begin{array}{l}\text { Identify the parts of the song and break it down as needed. } \\
\text { Reuse solutions developed to solve the same problem, } \\
\text { avoiding rewriting. }\end{array}$ & 1 and 2. \\
\hline $\begin{array}{l}\text { Pattern } \\
\text { Recognition }\end{array}$ & $\begin{array}{l}\text { Identify patterns in the sounds produced by the piano keys. } \\
\text { Reuse instructions through repetitions and conditions (for } \\
\text { example, the chorus that is repeated in the song). }\end{array}$ & 1,3 and 4. \\
\hline Algorithms & $\begin{array}{l}\text { Formalize the sequence of steps needed to solve the problem. } \\
\text { Refine the solution. }\end{array}$ & 1 and 5. \\
\hline
\end{tabular}

Additionally, Scratch interfaces with other technologies that are very interesting for the development of music activities. One of them is the tangible interface MakeyMakey which has a set of plug-ins for creating music on specific musical instruments [MakeyMakey Plugins 2021] as well as the MicroBit electronic board [MicroBit Plugins 2021] that even allows the creation of real physical objects, these may be musical instruments - consult the plug-ins in the music topic.

\section{Final Considerations}

Music in Basic Education contributes to the integral formation of the child, as it gives access to the playful and interactive world where the child expresses himself and creates his own representation of the world. Still, music in education must go beyond these conceptions, and must be used as an instrument that enhances and facilitates the development process, thus completing a pleasurable formation of knowledge that the individual builds.

In this sense, the study proposed a model of experimental activity (fully customizable) using a digital resource to promote new options for teaching learning in the field of music, in line with the BNCC guidelines and the exercise of Computational Thinking skills, which is fundamental in the contemporary world.

The intention of digital music production is linked with play, with the possibility of taking risks, testing new things and testing limits so that "thinking while playing" becomes a process of manipulation, experimentation and exploration that are fundamental characteristics of learning creative. Allied to this, learning a programming language these days is as important as learning to read and write.

Finally, as future works, it is intended to explore new approaches in the field of music in the Early Childhood Education stage using Scratch Junior, creating new possibilities for adaptation to online, ED and hybrid teaching - which tends to be maintained in the post-COVID-19. 


\section{Acknowledgment}

This research was partially supported by the NICO Project (PID2019-105455GB-C31) of the Spanish Government's Ministry of Economy and Competitiveness.

\section{References}

BRASIL. Ministério da Educação (2017). National Education Standards. Available in: http://download.basenacionalcomum.mec.gov.br/. Accessed JUN 2021.

Bresler, L. Pesquisa qualitativa em educação musical: contextos, características e possibilidades. Revista da ABEM, Porto Alegre, Volume 16, p. 7 - 16, 2007.

Duarte, R. A construção da musicalidade do professor de educação infantil: um estudo em Roraima. Tese (Doutorado em Educação) Universidade Federal do Rio Grande do Sul, Porto Alegre, 2010. $213 \mathrm{f}$.

Dubey, S., Biswas, P., Ghosh, R., Chatterjee, S., Dubey, M. J., Chatterjee, S. \& Lavie, C. J. (2020). Psychosocial impact of COVID-19. Diabetes \& Metabolic Syndrome: Clinical Research \& Reviews, 14(5), 779-788.

Fucci-Amato, R. Escola e educação musical: (Des)caminhos históricos e horizontes. Campinas, SP: Papirus, 2012.

Guarda, G. F.; Pinto, S. C. C. S. Dimensões do Pensamento Computacional: conceitos, práticas e novas perspectivas. In: SIMPÓSIO BRASILEIRO DE INFORMÁTICA NA EDUCAÇÃO, 31. 2020, Online. Anais [...]. Porto Alegre: Sociedade Brasileira de Computação, 2020. p. 1463-1472. DOI: https://doi.org/10.5753/cbie.sbie.2020.1463.

Papert, S. (1985). Logo: Computadores e Educação.

Papert, S. An exploration in the space of mathematics educations. Int'1 Journal of Computers for Mathematical Learning 1, 1 (1996), 95-123; http://www.papert.org/articles/AnExplorationintheSpaceofMathematicsEducations.

Plugins MakeyMakey. 2021. Available in: https://makeymakey.com/blogs/how-toinstructions/apps-for-plug-and-play. Accessed JUN 2021.

Plugins MicroBit. 2021. Disponível em: https://makecode.microbit.org/. Accessed JUN 2021.

Schafer, R. M. O ouvido pensante. 2. edição. São Paulo: UNESP, 2011.

Singh, J., \& Singh, J. (2020). COVID-19 and its impact on society. Electronic Research Journal of Social Sciences and Humanities, 2.

UNESCO (2015) “TIC na educação do Brasil". Available in: http://www.unesco.org/new/pt/brasilia/communication-and-information/access-toknowledge/ict-in-education/. Accessed JUN 2021.

Wing, J. M. (2006, March). Computational thinking. Communications of the ACM, 49(3), 33-35. DOI: 10.1145/1118178.1118215.

Wing, J. Computational thinking. What and why? Carnegie-Mellon School of Computer Science Research Notebook (Mar. 2011). Available in: https://www.cs.cmu.edu/link/research-notebookcomputational-thinkingwhat-and-why.

Zhang, L.; Nouri, J. A systematic review of learning computational thinking through Scratch in K-9. Computers \& Education 141 (2019) 103607. DOI: 10.1016/j.compedu.2019.103607. 